\title{
In vitro Techniques and Plant Morphogenesis: Fundamental Aspects and Practical Applications
}

\author{
Rajbir S. SANGWAN*, Brigitte S. SANGWAN-NORREEL* and Hiroshi HARADA** \\ * Université de Picardie Jules Verne, Laboratoire Androgenèse et Biotechnologie, 33 \\ rue Saint-Leu, 80039 Amiens, France \\ ** Agricultural Research \& Trainig Center, Tsunozawa, Shinjo, Yamagata Japan
}

Received 12 May 1997; accepted 15 May 1997

\begin{abstract}
Plant cell and tissue culture together with the recent advances in recombinant DNA technology are getting great attention because these are the sources of innovation for the major agricultural industries and practice. However, despite the many successful applications of plant tissue culture in agriculture and horticulture, differentiation and especially plant regeneration, remain a major problem with a number of crop species. Relatively few crop species are capable of predictable regeneration. Even in those instances where regeneration has been reported, e.g. Nicotiana, Petunia and Arabidopsis, through empirical selection of explants and media, problems are often encountered with particular cultivars within a species. Hence, these problems constitute a serious block to crop improvement. Moreover, a detailed characterization of the competent host plant cell will be required if we are to further exploit the Agrobacterium system for transformation of recalcitrant plant species. In this review article we describe some possible opportunities which may lead to rational plant improvement.
\end{abstract}

\section{Introduction}

With the first success in in vitro culture of plant tissues $[1,2]$ a new technology based on the manipulation of the living material was born in 1930-40's. Since then, this technology has developed considerably and today it plays a key role in plant improvement and genetic engineering. Several workers have reviewed the strategic approaches for development of reliable systems for plant regeneration and their application in plant biotechnology [3-6]. Some of the important landmarks in the in vitro technology are:

-Gautheret, Nobécourt, and White achieved the first success in developing plant tissue culture, e.g. Gautheret [1] obtained continuous callus proliferation in cultured explants of carrot root and tree stem in 1939.

-Skoog and co-workers [7] discovered cytokinins. They also observed that the shoot and root formation are controlled by the auxin/ cytokinin balance in late 1950's.

-Steward et al. [8] and Reinert [9] described in vitro somatic embryogenesis in 1958.

-Guha and Maheshwari [10,11] discovered haploid production from anther culture in 1962.

-Protoplast culture, fusion, and development of somatic hybrids were described in the 1960's and 1970's [12, 13].

-Recombinant DNA technology and production of transgenic plants were obtained in 1980's [14 $-17]$.

\section{Clonal propagation and production of virus- free plants}

Micropropagation has changed from a laboratory curiosity to a commercial industry, and offers many advantages over the conventional method of multiplication of plants. It is often cited as the most successful example of the use of plant biotechnology. In vitro multiplication involves two main pathways:

-True to type multiplication of plants from programmed/existing meristems (axillary and apical meristems, microtubers). The production of virusfree plants, especially vegetable and ornamental crops, falls into this category.

-Multiplication through de novo neoformation and somatic embryogenesis. This de novo pathway concept is based on totipotency of the cells, i.e., each cell possesses the genetic information leading to the formation of a complete plant. In future, the major breakthroughs for plant improvement, e.g. artificial seeds, genetic engineering, somaclonal variation or mutation, will be based on this technonoly.

The ability of plant cells to regenerate via embryo or organ formation in liquid cultures can be exploited for large scale in vitro multiplication and automation 
[18]. However, abnormal shoot/organ formation and isolation of single propagule still limit efficient in vitro multiplication in liquid media. The control of shoot morphogenesis in liquid media can be attained by the control of culture condition which will limit or prevent leaf expansion and shoot growth, while at the same time enhance proliferation. The growth retardants such as Ancymidol(GA synthesis inhibitor) which inhibited leaf development and induced rounded meristematic clusters have also been used.

More than 100 plant species have been studied in order to determine the conditions of in vitro regeneration. Various combinations of nutrients, phytohormones, and environmental factors have been listed, although an important determinant is the physiological status of the starting explant. In order to maintain genetic stability, micropropagation should be initiated from organised meristems. Micropropagation is the most widely and successfully used technology by private companies for the mass production of horticultural plants. For example, ornamental crops (gerberas, ferns, roses, carnations, lilies, etc.), vegetables (tomato, carrot, celery and others), food crops (cassava, potato, sugarcane), fruits (banana, pineapple, apple, strawberry, cherries, etc.), plantation crops (coconut, tea, cacao) and spices (clove, cinnamon, ginger, turmeric) have been routinely multiplied in vitro. The success has been relatively rapid with herbaceous crops, but the progress in perennial horticultural and plantation crops has been slow due to the lack of basic genetic information and their recalcitrance to regenerate in cultures.

Moreover, the extension of micropropagation to species normally propagated by seeds, can be considered if production costs decrease. Therefore, to assure the future of micropropagation, production cost should be reduced, either by locating the micropropagation industry in zones where labour is cheap such as in Asia, South America, and Africa, or by introducing automation and robotics [18].

\section{Somatic embryogenesis and artificial seeds}

In 1958, Steward et al. [8] and Reinert [9] independently observed for the first time the phenomenon of somatic embryogenesis in cultured carrot tissues. The embryo-like structures developed into plantlets and then formed an entire plant. However, these two studies did not permit to show the first stages of embryo development leading to the formation of plantlets. Later Halperin and Wetherell [19] showed in the carrot callus the true embryos passing through the morphological stages very similar to that of zygotic embryos. Since then, similar results have been reported in several plant species. Indeed until now more than 150 plant species have been shown to follow the process of somatic embryogenesis. Among the various plant species studied, only the carrot has been widely used. It is considered the best plant model to study the factors controlling plant embryogenesis. In all cases studied, the morphological aspect of embryonic development is comparable to those of seed embryos, but the factors favouring this process are different from the seed embryo. Three groups of factors have been identified in carrot : a) the type of the initial explant, b) the condition of the culture and c) the composition of the medium.

\section{a) Type of initial explant}

For each plant species used, certain organs appear to be more favorable than others for the neoformation of the embryos. The most embryogenic organs vary from plant to plant, e.g. floral buds and stem segments for Ranunculus, stem segments for Foeniculum, petiole for carrot [20] and Coffea [21]. The maturity of the organs sometimes modified their embryogenic potential. Staritsky [21] reported that only the young petioles of Coffea gave embryogenic calli. Generally, it has been reported that leguminous crop species and woody plants are extremely difficult to regenerate via somatic embryos from differentiated organs such as root, leaf and stem, by conventional in vitro techniques [22]. However, immature zygotic embryos have provided an alternative source of explant tissues for regeneration at high frequencies and without apparent somaclonal variation in these species [22]. One possible explanation for this success is that cells in the zygotic embryos have undergone only a few cell divisions after completing fertilization and meiosis. These cells may thus remain totipotent and more responsive to in vitro manipulation. Direct somatic embryogenesis has frequently been reported from immature zygotic embryos and in certain species efficient regeneration occurs only from zygotic embryo explants [22].

\section{b) Conditions of culture}

Although there is not much data on this aspect, culture conditions such as temperature and light do influence sometimes the frequency of somatic embryogenesis. For example, in carrot, a dark period (or a low light intensity) is frequently used for the induction of embryogenic callus. Kamada et al. [23] induced somatic embryos in carrot using a heat stress treatment. For example, when apical-tip segments were cultured at 35 or $37^{\circ} \mathrm{C}$ during $1-2$ weeks and then transferred to $25^{\circ} \mathrm{C}$ in the light, somatic embryos were formed at a low (3 to 17\%) frequency. The embryos were formed on the surface of the elongating true leaves without visible callus forma- 
tion. Apical-tip segments that were cultured at 40 or $42^{\circ} \mathrm{C}$ died within a few days of culture with the loss of chlorophyll. Moreover, in order to clarifiy the duration of heat treatment, the apical-tip segments were cultured at 40 or $42^{\circ} \mathrm{C}$ for 2 to $72 \mathrm{~h}$ and then transferred to $25^{\circ} \mathrm{C}$, but no embryos had developed. Among all of the different treatments tested, culture at $37^{\circ} \mathrm{C}$ for 3 weeks was the most effective. According to these authors stress (including high temperature treatment) induction of carrot somatic embryos without phytohormone treatment, provides a new tool to investigate the mechanism of embryogenesis and especially the acquisition of embryogenic competence.

\section{c) Composition of the medium}

The presence of growth substances in the medium is one of the main factors for the initiation of somatic embryogenesis. In particular, the role of auxins in inducing somatic embryogenesis has been demonstrated by many authors. Although 2,4-D was generally used [19] sometimes IAA and other auxins [20] have also been used.

In carrot, embryogenic callus was formed on petiole explants when cultured on auxin-containing medium. Somatic embryos were formed after transfer of these calli to auxin-free medium. In suspension culture, formation of somatic embryos can be synchronized by enriching the suspension with small, dense clusters of embryogenic cells [24]. This synchronized system has allowed investigations of the morphological, physiological, biochemical, genetic and molecular biological aspects of the embryogenesis [25-27].

Harada and collaborators have obtained somatic embryos without phytohormone treatments, i.e. when apical-tip segments were cultured on a high concentration of sucrose [28] or heavy metal ions such as cadmium or sodium chloride [26] in the phytohormone-free medium. In each case, embryos were formed directly on the surface of the elongating leaves without a visible callus formation. According to these authors chemical stress treatments including 2,4-D trigger the induction of somatic embryos and bring suitable changes for acquisition of embryogenic competence during the stress treatment. Somatic embryogenesis also generally depends upon the hormonal balance in the culture medium. It has been demonstrated that an embryogenic medium must have ammonium ions and a high level of auxin or the correct auxin/cytokinin ratio [29]. In all cases, the initiated proembryos must be transferred to hormonefree medium for further development.

Along with the basic understanding of the somatic embryogenesis, its potential use as artificial seeds, in a few cases such as carrot, alfalfa, celery and grape, has been reported. It has been suggested that for the mass production of embryos (which can be separated by automatized process) and synchronization of their development, a liquid medium is most appropriate. The somatic embryos can be fractionated into several groups of varying size by passing through stainless steel sieves, and encapsulated in calcium alginate to make synthetic seeds $[30,31]$. In carrot, these synthetic seeds germinated 1 to 2 weeks after sowing [31]. The problems related in the use of somatic embryos as artificial seeds can be summerized as below:

-determination of the conditions in large scale cell culture (Bioreactors),

-synchronization of embryo induction and development,

- conservation of the embryogenic potential,

-isolation of single embryo,

-limitation of secondary embryogenesis,

-maintenance of the conformity,

-determination of the encapsulating media and automation,

-embryo germination and their agronomic performance, and,

-cost comparison with the natural seeds.

For detail discussion of these points, interested readers are guided to the review papers $[18,30-32]$.

\section{Pollen embryogenesis and haploid production}

General methods for the induction and development of haploid embryos, calli and plants from anther/ pollen culture and breeding through haploid androgenesis are now well established [33-36]. For example, plant breeders quickly recognized the value of in vitro production of haploids for plant improvement since doubled haploids provide immediate homozygosity and the recovery of alleles not expressed in the heterozygous state, thus eliminating the need for selfing and to a limited extent for repeated backcrossing. During the 1970 's, notable efforts were made to investigate the initial stages of pollen embryo morphogenesis, culture conditions, growth hormones and subsequent development stages for complete plant formation. Thus, recently anther and pollen culture has emerged as one of the new and more promising techniques for the mass production of haploids and dihaploids.

The discovery by Guha and Maheshwari [10] at the University of Delhi that haploid embryos and plants could be obtained by in vitro culture of immature anthers of Datura innoxia created considerable excitement among tissue culturists and plant breeders. Consequently, it was visualized that it would soon be possible to produce large numbers of haploid embryos and plants. Soon after, Nitsch and collaborators 
[37] showed that normal haploid green plants in large number could be obtained within a short time (5-7 weeks) by anther culture in several species of Nicotiana. Isolated microspore culture technique is now routinely used both in the model and agronomically important plants such as Nicotiana, Brassica, wheat, barley, maize and rice [33, 36, 38-40]. Since the successful induction of haploids in Datura and Nicotiana from immature anther culture, numerous articles and reviews $[33,36]$ have appeared. These reviews give a far wider coverage of the literature than is possible here. Although significant progress has been made in in vitro androgenesis, it has not yet developed to the point where male gametes can be manipulated at will. This is particularly true in crop species. However, many researchers now have this target in mind and we think that contemporary advances in cell culture technology will result in accomplishing this goal in the near future. Once this goal is reached, several additional applications of in vitro immature pollen culture will be complimented by recombinant DNA technology. For example, genetic transformation of pollen embryos could be used in plant breeding. In this review, we describe haploid production and its applications with special attention being given to the general cytophysiology of pollen embryogenesis and to the factors which control in vitro androgenesis. We have confined our remarks to the more recent developments which have led to changes since the last reviews appeared. It is obvious that there are numerous other contributions to this technology and therefore we direct readers to the earlier reviews $[33,36]$ for more details. The fundamental studies are aimed at determining how and why the haploid embryos are formed as well as the particularities of the regenerated plantlets. Following these studies this phenomenon can be divided into three stages which differ most frequently in their characteristics: induction of embryos, the development of embryos and their germination.

\section{1 Characteristic of embryo induction and development}

Induction corresponds to a change in the morphogenetic pathway of pollen. It is the time when the development of a gametophyte orients towards the realization of a new genetic program of embryogenesis instead of continuing its normal gametophytic pathway. The characteristic of this induction is its low frequency. The percentage of embryogenic pollen remains always very low. It has been observed that among all plant species tested only a few gave embryogenic pollen development. Moreover, for the same plant species, major differences have been observed even among the varieties, suggesting a strong effect of gynotype. For example, we found in Datura the percentage of embryogenic pollen rarely exceeded $8 \%$ [33]. More often the frequency of embryogenic pollen is close to $1 \%$ or even less, as reported by several authors for other plant species. This may suggest that haploid embryogenesis is under the specific control of one or more genes which are not present in all the gametophyte.

Based on the studies of several plant species, including Datura, Nicotiana, Brassica and barley, several key factors influencing in vitro androgenesis have been identified. Theses are: 1) pollen stage, 2) culture medium, 3) stress treatment.

\subsubsection{Effect of pollen stage}

The importance of pollen stage for the production of pollen embryos was first recognized by Nitsch [37]. They found that the uninucleate stage was the most favorable for pollen embryogenesis in Nicotiana. Since, Norreel [41] has determined precisely the pollen stages the most favorable for embryogenesis in Nicotiana and Datura. She found that this favourable period lies between the late uninecleate (for Datura) to early binucleate (for Nicotiana) stages of pollen development. This has now been confirmed in other plant species by several groups. Pollen stage is also important with regard to the ploidy level of the embryos produced. In Datura, Norreel [42] observed that microspores at the tetrad stage gave mainly haploid embryos, while binucleate pollen grains formed embryos of higher ploidies $(2 n, 3 n, 4 n$, etc...).

\subsubsection{Effect of culture medium}

If the pollen stage is critical for the induction of pollen embryos, the culture medium appears to be less important for the early development of embryos. Indeed, Nitsch and Nitsch [43] showed that androgenesis can be initiated on a very simple medium containing $2 \%$ sugar and $0.8 \%$ agar. However, it should be noted that for further development of proembryos a relatively complex medium is required. Particularly, iron is necessary for embryo development [37]. Apparently, phyothormones have no notable effect, except for auxin which slightly increased the number of embryogenic anthers. In spite of this fact, relatively high concentrations of phytohormones are widely used in anther culture.

Raghavan and collaborators studied the role of 2,4D in anther cultures of Hyoscyamus [44]. They found that 2,4-D increased the number of embryogenic anthers but did not affect the number of embryogenic pollen grains. Higher concentrations of 2,4-D (> $20 \mathrm{mg} / l$ ) significantly reduced pollen callusing. Cyto kinins, such as kinetin, benzyladenine, and zeatin $\left(0.01^{-}\right.$ $10 \mathrm{mg} / l$ ) reduced pollen efficiency by as much as $40^{-}$ $60 \%$, even at low concentrations. With increasing concentrations of cytokinin there was a progressive 
delay in plantlet formation. According to Raghavan [44], all cytokinins except zeatin riboside inhibited embryogenic growth in anthers of henbane. In species such as cereals, where pollen callus formation was observed, addition of cytokinin alone or with auxin and other organic compounds in complex combinations made it difficult to determine whether auxin or cytokinin or a combination of both was necessary to induce callus growth. It has also been argued that since the tapetum is a source of nutritive substances for developing pollen grains, tapetum may supply the phytohormones necessary for the development of pollen embryos.

\subsubsection{Stress treatments}

Among the several stress treatments applied to floral buds or anthers prior to in vitro culture, cold treatment has been shown to increase considerably the frequency of embryogenic pollen in Datura and Nicotiana $[45,46]$. We have also studied the effect of cold treatment on amino acid metabolism and ultrastructural changes occurring in anthers and pollen grains $[47,48]$. Certain amino acids such as glutamine and proline accumulated under the stress conditions and we proposed that they could play an important role in the induction period of androgenesis.

Several groups have convincingly shown the beneficial effect of elevated temperatures $\left(30^{\circ} \mathrm{C}\right.$ or more) in Brassica, egg plant and pepper [36, 49].

In the mid eighties, Kyo and Harada [39] developed a new method to fractionate and culture Nicotiana immature pollen grains which allowed biochemical investigations of pollen embryogenesis. During the course of their investigations, they found that two factors were essential for high frequency induction of embryogenic cell division. First, freshly isolated microspores must be cultured for more than 3 days in a medium lacking nutrients, in particular sucrose (starvation treatment) and then they must be supplied with suitable carbon and nitrogen sources. When freshly isolated immature pollen grains were cultured in a nutrient medium, a rapid accumulation of starch occurred and the grains burst and died within 24-28h. Second, embryogenic cell division was observed in pollen grains only at a specific developmental stage, $i$. $e$. mid-binucleate stage. In barley, the highest frequency of in vitro embryogenesis was obtained by a 4 day pretreatment of anthers with mannitol and a supply of oxygen at regular intervals [50].

Touarev et al.[51] have reported in Brassica napus that pollen isolated shortly before the first mitosis can be induced to form embryos by a heat-shock treatment at $33^{\circ} \mathrm{C}$ followed by culture at $25^{\circ} \mathrm{C}$. Similarly, the formation of embryogenic cells which developed into embryos was induced after transfer to a sugarcontaining medium. In both systems up to $50 \%$ of the pollen produced embryos [51]. In Nicotiana more than $50 \%$ of embryogenic pollen grains were observed after 6 days of starvation at $25^{\circ} \mathrm{C}$ and this value increased up to $70 \%$ when the starvation treatment was performed at $33^{\circ} \mathrm{C}$. In this species, embryogenesis could also be induced by a heat-shock treatment $\left(33^{\circ} \mathrm{C}\right.$ or $37^{\circ} \mathrm{C}$ for 3 days $)$ in the presence of sugar, however, a certain amount of pollen embryo development (20 to $25 \%$ ) was blocked at the globular stage. Brassica is known for its ability to produce high numbers of embryos in isolated microspore culture which have been treated for heat stress for $8 \mathrm{~h}$. Cordewener et al.[52] found that the microtubular cytoskeleton exhibited changes in its configuration leading towards changed cell division patterns and embryogenesis. Furthermore, DNA labelling experiments revealed that there was a change in the fate of the vegetative cell nucleus when cultured under embryo-inducing conditions. Changed patterns of DNA synthesis and cell division were preceded by a changed expression and distribution of heat shock proteins. These recent observations have considerably improve our understanding of the inductive phase of embryogenesis.

\section{Production of secondary metabolites}

It has been suggested that plant cell and tissue cultures grown on a large scale (bioreactors) can act as a source of continuous production of secondary metabolites or other valuable chemicals for pharmaceutical, food flavouring and colouring industries. Cultures of many species release their products to the culture media and this is particularly evident in immobilised cultures [53]. This leads to greater efficiency in extracting the phytochemicals, as plant tissue does not need to be processed. Moreover, the prospect of continuous product removal may also increase synthesis by reducing any feedback inhibition of regulating enzymes. Another advantage of cultured cells is that limiting precursors to biochemical pathways or single step biotransformations can be added to the culture medium at any stage of growth cycle which is not possible in whole plants. Also, the production of secondary metabolites from cell culture can be strictly controlled and almost free from the political and economic vagaries of the international commodity markets. Although, large advances in automated fermenter technologies have been made, the high cost of production with the small size of the market for these products has limited considerably the industrial applications of this technology. However, efficient in vitro production of "shikonin", a secondary metabolite used in cosmetic industry in Japan, has shown interesting possibilities [54]. Pro- 
duction of essential oils, flavours and other metabolites from cell cultures and hairy roots has already been reported from Mentha, lavender, rosemary, etc. [55], and hence may allow the expansion of this industry in the near future. Finally, the use of transgenic plants in the production of valuable secondary metabolites has the innate advantage of lower labour and capital costs than cell culture. If whole plants can be regenerated from transformed cells with altered secondary metabolism they can be used as "green bioreactors" to produce useful compounds grown on land surplus to traditional agricultural requirements.

\section{Genetic transformation}

It is only during the last decade that genetic engineering of plants has been developed and it has now become an important tool for crop improvement. This technology makes possible genetic manipulations that were outside the repertoire of conventional breeding and cell fusion techniques. At present, genes can be taken from completely unrelated organisms: plants, animals, bacteria, viruses, and can be introduced into a desired crop plant. Now it is possible to transfer specific and well-characterized traits across the broadest evolutionary boundries. However, the application of recombinant-DNA technology for crop improvement is dependent on the availability of efficient systems for the transfer of foreign genes into cells capable of regenerating fertile plants. In recent years, a range of techniques have been developed to transform plant cells with specific pieces of DNA. These techniques are based on Agrobacteriummediated gene transfer and direct DNA transfer, and have been extensively reviewed over the last few years $[5,14,56-58]$. Using these techniques of gene transfer, transgenic plants have been obtained in about 100 plant species, and their number is increasing rapidly. At present transgenic plants resistant to herbicides, to distructive insects and to viruses have been obtained $[5,59]$. Considering the fact that enormous plant losses are caused by weeds, insects and viruses in modern agriculture, the theoretical saving effected by such transgenic crop plants will be substantial. For example, Goldberg and his associates [60] obtained complete male sterile plants in tobacco and oil seed-rape by using recombinant DNA technology. These male sterile plants may be efficiently used for commercial production of hybrid seeds. Still another example relates to possibilities of altering processes connected with senescence of fruits such as tomato which can lead to production of fruits that will last longer or otherwise lead to more convenient harvesting practices [61]. Several interesting exam- ples of stress (cold and draught) tolerance either by using anti-freeze protein gene or choline dehydrogenase have been reported [62,63]. Recently, fungal resistant chitinase and glucanase genes which digest fungal cell walls have also been used [64]. Other examples involving the manipulation of floral colors and formes as in petunia [65] and extension of the shelf-life of flowers and fruits through genetic engineering has been reported $[66,67]$.

Although the successfull genetic manipulation of certain plants is at hand, important crop species like cereals and grain legumes, are still rather difficult because methods for their transformation and regeneration are far from routine. However, recently two Japanese groups using supervirulent strains of $A$. tumefaciens successfully transformed embryogenic cell lines of rice $[68,69]$ and maize $[70]$ and obtained transgenic plants. These results have considerably increased the interest in the use of Agrobacterium for gene transfer to monocot.

\section{Conclusions and perspectives}

Here, we have discribed diverse potentialities of in vitro techniques for plant propagation and improvement. There is no doubt that in vitro embryogenesis and development of entire plants from such a system, is a powerful tool that we can apply to plant propagation and improvement. The concept of artificial seeds would probably become a reality, most likely in high cost $F_{1}$ hybrid ornamental plants and in conifer clonal forestry. However, much yet remains to be learned regarding the more precise physiology of early embryo development and the interaction of various factors during this period. It seems certain that as our knowledge of embryo development in Angiosperms increases, biochemical and molecular techniques will assume increasing importance in the analysis of embryogenesis. Many attempts are in progress to understand the embryogenic development at the genetic and molecular level and they have recently been reviewed $[71,72]$. One of the main difficulties at present is to identify and correlate the developmental phases with the specific biochemical and molecular markers in somatic and pollen embryogenesis [73]. The one promising approach could be the phytohormonal control of gene expression during somatic embryogenesis. This, however, requires highly synchronous embryogenic systems.

The possibilities of genetic engineering are in fact limitless ranging from agriculture to pharmaceutical industry, e.g. production of biologically active peptides as chimeric seed proteins, neuropeptides, blood factors and growth hormones [74].

Finally, the above accounts may give the impression 
that the future lies all in applied research. This, however, is not the case and advances in plant biotechnology do require more basic research and more public funding along with time and man-power. It is needless to say that the fundamental knowledge of plant growth and development and its molecular control will be essential to obtain many of the objectives discussed above.

\section{Acknowledgments}

We thank Mrs. M. Poiret and K. Pouillaude for technical assistance.

\section{References}

[1] Gautheret, R.J., 1939. C.R. Acad. Sc., Paris, 208: 118-120.

[2] White, P.R., (ed.) 1943. In "A Handbook of Plant Tissue Culture”, J. Casttell Press, Lancaster, USA.

[ 3 ] Vasil, I.K., 1990. IAPTC Newsletter, 62: 2-11.

[4] Vasil, V., 1994. Plant Cell, Tissue Org. Cult., 39: 105-108.

[5] Sangwan, R.S., Sangwan-Norreel, B.S.,(ed.) 1990. In "The Impact of Biotechnology in Agriculture”, Kluwer Acad. Publishers, Dodrecht, Boston, London.

[6] Lowe, K.C., Davey, M.R., Power, J.B., 1996. Plant Tissue Culture and Biotechnol., 2: 175-187.

[7] Skoog, F., Miller, C.O., 1958. Symp. Soc. Exptl. Biol., 11: 118-130.

[8] Steward, F.C., Mapes, M.O., Mears, K., 1958. Am. J. Bot., 45: 693-713.

[9] Reinert, J., 1958. Naturwiss., 45: 344-345.

[10] Guha, S., Maheshwari, S.C., 1964. Nature, 204: 497.

[11] Bourgin, J.P., Nitsch, J.P., 1967. Ann. Physiol. Vég., 9: 377-382.

[12] Cocking, E.C., 1960. Nature, 187: 927-929.

[13] Gleba, Y.Y., Sytnik, K.M., (eds.)1984. In "Protoplast Fusion: Genetic Engineering of Higher Plants", Springer-Verlag, Heidelberg.

[14] Schell, J., 1987. Science, 237: 1176-1183.

[15] Schell, J., Vasil, K., (eds.)1989. In "Cell Culture and Somatic Cell Genetics of Plants", vol. 6, "Molecular Biology of Plant Nuclear Genes", Academic Press, New-York.

[16] Zupan, J.R., Zambryski, P., 1995. Plant Physiol., 107: 1041-1047.

[17] Siemens, J., Schieder, O., 1996. Plant Tissue Culture and Biotechnol., 2: 66-76.

[18] Takayama, S., Akita, M., 1994. Plant Cell Tissue Org. Cult., 39: 147-156.

[19] Halperin, W., Wetherell, D.F., 1964. Amer. J. Bot., 51: 274-283.

[20] Norreel, B., Nitsch, J.P., 1968. Bull. Soc.
Bot. Fr., 115: 501-514.

[21] Staritsky, G., 1970. Acta Bot. Neerl., 19: 509514.

[22] Tétu, T., Sangwan-Norreel, B.S., Sangwan, R.S., (eds.) 1990. In "The Impact of Biotechnology in Agriculture”, p.171-189, Kluwer Academic publishers, Dodrecht, Boston, London.

[23] Kamada, H., Tachikawa, Y., Saitou, S., Harada, H., 1994. Plant Tissue Culture Letters, 3: 229232.

[24] Fujimura, T., Komamine, A., 1979. Plant Physiol., 64: 1162-1164.

[25] Nomura, K., Komamine, A., 1986. Oxf. Surv. Plant Mol. Cell Biol., 3: 456-466.

[26] Kiyosue, T., Satoh, S., Kamada, H., Harada, H., 1993. J. Plant Res. Special Issue, 3: 75-82.

[27] Van Engelen, F.A., De Vries, S.C., 1992. Trends Genet., 8: 66-70.

[28] Kamada, H., Kobayashi, K., Kiyosue, T., Harada, H., 1989. In vitro Cell. Dev. Biol., 25: 1163-1166.

[29] Sangwan, R.S., Harada, H., 1975. J. Exp. Bot., 26: 868-881.

[30] Redenbaugh, K., Walker, K., 1990. In "Plant Tissue Culture: Application and Limitations" (ed. by Bhojwani, S.S.), p.102-136, Elsevier, Amsterdam.

[31] Harada, H., Kiyosue, K., Kamada, H., Kobayashi, K., 1990. In "The Impact of Biotechnology in Agriculture”, (eds. by Sangwan, R.S., Sangwan-Norreel, B.S.), p.129-159, Kluwer Academic Publishers, Dordrecht, Boston, London.

[32] Merkle, S.A., 1995. Plant Tissue Culture and Biotechnol., 1: 112-122.

[33] Sangwan, R.S., Sangwan-Norreel, B.S., 1987. Int. Rev. Cytol., 107: 221-272.

[34] Sangwan, R.S., Sangwan-Norreel, B.S., 1990. In "Plant Tissue Culture: Applications and Limitations" (ed. by Bohjwani, S.S.), p.220-241, Elsevier, Amsterdam.

[35] Pauls, K.P., 1996. In "In Vitro Haploid Production in Higher Plants" (eds. by Jain, S.M., et al.),vol. 1, p. 125-144, Kluwer Acad. Publishers, Dodrecht.

[36] Jain, S.M., Sopory, S.K., Veilceux, R.E., 1996.In "In Vitro Haploid Production in Higher Plants", (eds. by Jain, S.M., et al.), vol. 3, Kluwer Acad. Publisher, Dodrecht.

[37] Nitsch, J.P., 1969. Phytomorphology, 19: 389404.

[38] Sangwan, R.S., Norreel, B., 1975. Nature, 257: 222-224.

[39] Kyo, M., Harada, H., 1985. Plant Physiol., 79: 90-94.

[40] Takahata, Y., Komatsu, H., Kaizuma, N., 1996. 
Plant Cell Rep., 16: 163-166.

[41] Norreel, B., 1970. Bull. Soc. Bot. Fr., 117: 461-478.

[42] Norreel, B., 1975. In "Etude Physiologique, Cytochimique et Ultrastructural de l'Embryogenèse Somatique chez le Daucus Carota et de l'Androgenèse chez le Nicotiana et le Datura", Thèse de Doctorat d'Etat, Université Pierre et Marie Curie, Paris VI.

[43] Nitsch, J.P., Nitsch, C., 1969. Science, 163: 8587.

[44] Raghavan, V., Nagmani, R., 1989. Can. J. Bot., 67: 247-257.

[45] Nitsch, C., Norreel, B., 1973. C.R. Acad. Sci., Paris, 276: 303-306.

[46] Sangwan-Norreel, B.S., Sangwan, R.S., Paré, J., 1986. Bull. Soc. Bot., Fr., 133. Actual. Bot., 4: 7-39.

[47] Sangwan, R.S., Camefort, H.,1984. Cytologia, 49: 473-487.

[48] Camefort, H., Sangwan, R.S., 1979. C.R. Acad. Sc., Paris, 288: 1383-1386.

[49] Pechan, P.M., Keller, W.A., 1988. Physiol. Plant., 74: 377-384.

[50] Hoekstra, S., Van Zijderveld, M.H., Heidekamp, F., Van der Mark, F., 1993. Plant Cell Reports, 12: 661-665.

[51] Touarev, A., Ilham, A., Heberle-Bors, E., Vincente, O., 1994. In "Frontiers in Sexual Plant Reproduction Research" (eds. by HeberleBors, E., Hess,M., Vincente,O.), p. 17, Univ. of Vienna, Autriche.

[52] Cordewener, J.H.G., Van Lammeren, A.A.M., Van Lookeren Campagne, M.M., 1995. Planta, 196: $747-755$.

[53] Williams, P.D., Mavituna, F., 1992. In "Plant Biotechnol.” (eds. by Fowler, M.W., Warren, G. S.), p. 63-78, Pergamon Press, Oxford.

[54] Yamada, Y., Fujita, Y., 1983. In "Handbook of Plant Cell Culture", (eds. by Evans, D.A., et al.), vol. 1, p.717-728, MacMillan, New-York.

[55] Dornenburg, H., Knorr, D., 1995. Enzyme Microb. Technol., 17: 674-684.

[56] Potrykus, I., 1990. Biotechnology, 8: 535-542.
[57] Songstrad, D.D., Summers, D.A., Griesbach, R.J., 1995. Plant Cell Tissue Org. Cult., 40: 1-15.

[58] Potrykus, I., Spangenberg, G., (eds.) 1995. In "Gene Transfer to Plants", Springer-Verlag, Berlin.

[59] Shah, D.M., Rommens, C.M.T., Beachy, R.N., 1995. Trends Biotechnol., 13: 362-368.

[60] Mariani, C., De Beuckeleer, M., Truettner, J., Leemans, J., Glodberg, R.B., 1990. Nature, 347: 737-741.

[61] Glovannoni, J.J., Dellapenna, D., Bennett, A.B., Fischer, R.L.,1989. Plant Cell, 1: 53-63.

[62] Kenward, K.D., Altschular, M., Hildebrand, D., Davies, P.L., 1993. Plant Mol. Biol., 23: 377385.

[63] Lilius, G., Holmberg, N., Bulow, L., 1996. Biotechnol., 14: 177-180.

[64] Zhu, Q., Maher, E.A., Masoud, S., Dixon, R.A., Lamb, C.J., 1994. Biotechnol., 12: 807-812.

[65] Mol, J.N.M., Holton, T.A., Koes, R.E., 1995. Trends Biotechnol., 13: 350-355.

[66] Good, X., Kellog, J.A., Wagoner, W., Langhoff, D., Matsumura, W., Bestwick, R.K., 1994. Plant Mol. Biol., 26: 781-790.

[67] Grierson, D., Schuch, W., 1993. Phil. Trans. Roy. Soc. Lond. B., 342: 241-250.

[68] Hiei, Y., Ohta, S., Komari, T., Kumashiro, T., 1994. Plant J., 6: 271-282.

[69] Rashid, H., Yokoi, S., Toriyama, K., Hinata, K., 1996. Plant Cell Rep., 15: 727-730.

[70] Ishida, Y., Saito, H., Ohta, S., Hiei, Y., Komari, T., Kumashiro, T.,1996. Nature Biotechnol., 14 : 745-750.

[71] Komamine, A., Kawahara, R., Matsumoto, M., Sunabori, S., Toya, T., Fujiwara, A., Tsukahara, M., Smith, J., Ito, M., Fukuda, H., Nomura, K., Fujimura, T., 1992. In Vitro Cell Dev. Biol., 28: 11-14.

[72] De jong, A.J., Schmidt, E.D.L., De Vries, S.C., 1993. Plant Mol. Biol., 22: 367-377.

[73] Goldberg, R.B., Baker, S.J., Perez-Grau, L., 1989. Cell, 56: 149-160.

[74] Mason, H.S., Arntzen, C.J., 1995. Trends Biotechnol., 13: 350-355. 